\title{
Uriel Giraldo y su «INSISTENCIA EN LA TIERRA»
}

Alberto Verón

Cronisia Cultural

Periodista Uniersidad Tecnológica de Pereira

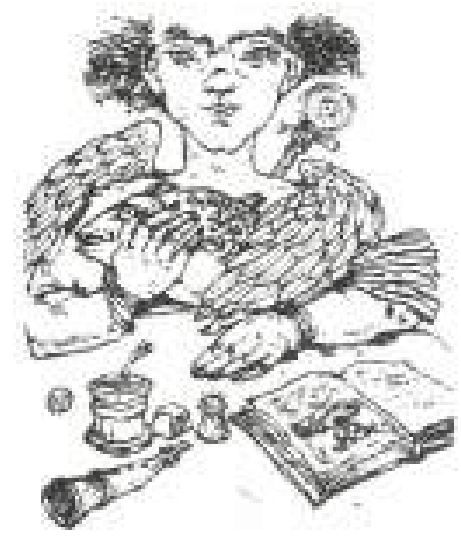

n Caldas, durante los años ochenta, aparecieron una serie de poetas que poco se nombran, muy a pesar de su valor actual, del cual la posteridad podrá agregar otras calificaciones: se trata de Oscar Jurado, Edgardo Escobar, Rodrigo

Acevedo, quienes en la tradicional Manizales aparecen con unos registros novedosos para su tiempo. A estos les correspondió introducir en su medio acentos de corte moderno; acentos que rompieron con la estética hispánica neoclásica representada en la primera mitad del siglo XX por Don Rafael Maya, uno de los criticos con mayor influencia en su época y quien trato de volver extensiva a la sociedad colombiana una profunda desconfianza por las voces en ascenso de la poesia modernista; voces a las cuales increpó y acusó por «La abusiva libertad que se tomó el poeta 
al quebrantar un precepto literario, (..) indicio de que ya en el fondo de los espiritus se fermentaba una vasta revolución cuyo sentido iba a consistir en la quiebra de los ideales más caros de la humanidad. El primerverso descoyuntado indicaba que algo se habia roto, igualmente, en la conciencia humana. La quiebra del ritmo silábico anunciaba un desequilibrio entre las antiguas y esenciales necesidades del alma, $y$ la bárbara imposición de un tiempo sin escrúpulos, sin piedad y sin bellezam. (1) Lo que para Rafael Maya resultaba apenas un momento coyuntural y pasajero de la poesia, ha en- contrado a lo largo de todo esta siglo un camino, que como bien lo expresa Marshall Berman (2) fue capez de movilizar fronteras. lenguas y sensibilidades. La modernidad -no tan joven ya, con ciento cincuenta años encimaconsiguió ztravesar los géneros estructurados en el clasicismo y constituyo toda una serie de nuevas órbitas gracias a las cuales el ejercicio mismo de la poesia, sus acentos y sus temas se vuelven en posibilidades de comunicación.

\section{Tambièn como Uriel mismo} lo confiesa, su poesia tiene tempranos referentes en las veladas literarias que durante la dếcada de los ochenta hiciera en la ciu-

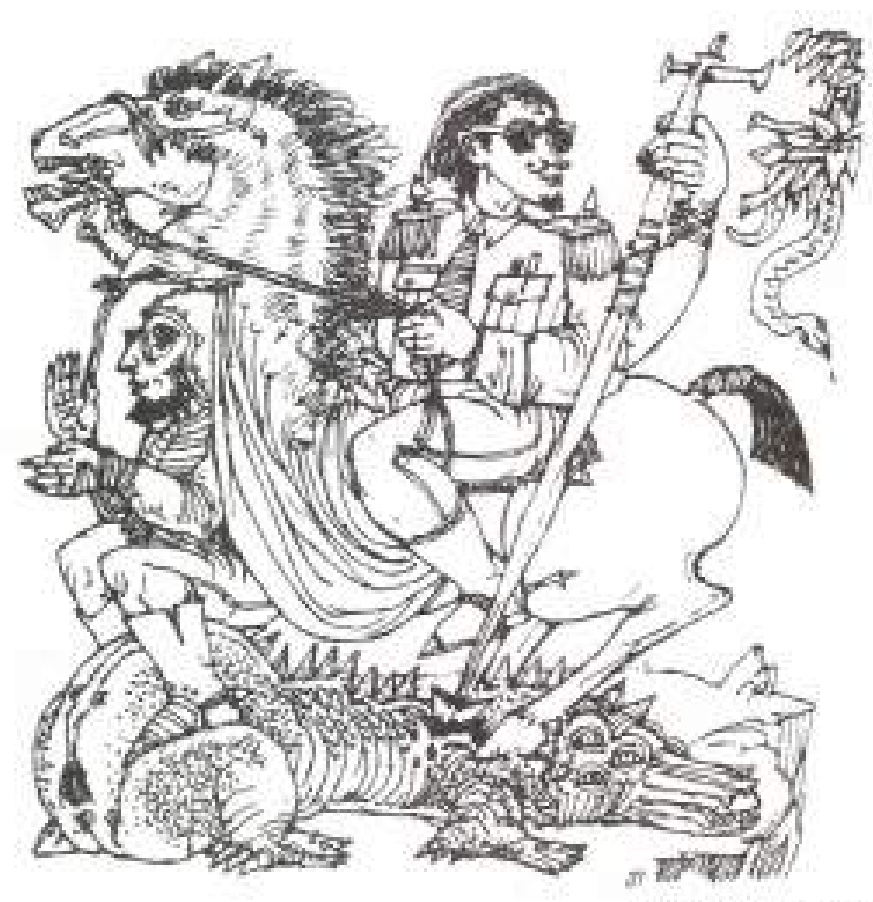

Dus foret $r$ d drayes dad Dorian Uribe Gonzalez, de forma insular y espontánea. Por esas veladas pasaron Luis Vidales, Juan Manuel Roca entre otros, quienes dejaron en el ambiente de aquellos años una huella que marcaria a los cofrades de esas veladas.

Fue aquel ambiente el indicado en Manizales para acabar con la tradición clásica defendida por Rafael Maya; era una potencia nueva, dispuesta a recibir otros acentos, ritmos de la cotidianidad, de la calle, del ciudadano corriente, de los entornos urbanos.

No olvidemos la manera que esos elementos hispánicos y católicos a los que hemos hecho referencia, y los que Rafael Maya tanto defendió, tuvieron en Manizales aita resonancia, pues la ciudad era cuna de una escritura literaria a la cual se le conoció como el $\alpha$ Greco Quimbayismon. Los ecos de aquella literatura, lograron disolverse gracias a la aparición de poetas signados por la estética modernista centrada en la ruptura. Pero también es conveniente sumar la presencia de un elemento aleatorio que ha cumplido papel de tónico, ya que oxigenó con otras tendencias artisticas y actitudes vitales el ambiente de la ciudad: nos referimos al Festi- 
val Universitario de Teatro

Recordamos esos aspectos. porque fue este el ambiente nutricio de una poética que se ha mantenido en su sencillez y pudor fiel a una sensibilidad: la moderna, a pesar de vivir entre una cultura de fundamentos tradicionales, en la cual se evidencian con la tonalidad de provincia las contradicciones que a lo largo de este siglo ha vivido nuestra sociedad. El diagnóstico realizado por Armando Romero (3) dibuja el ambito del cual se desprendió la poética de Giraldo: «L a dualidad formal del pensamiento político y cultural colombiano estả representada por la tendencia liberal y conservadora, que, como hemos dicho antes, remontan sus origenes al siglo pasado. Estando el poder en manos de una clase soeial alta, estas corrientes, al tener que ocupar el mismo hảbitat, han formado una extraña simbiosis que, asi como en ocasiones ha paralizado por largas épocas, también ha generado una acción que făcilmente se confunde con el progreso (...) La linea descollante de la poesia colombiana, la que va de Silva hasta Mito (...) ha participado intimamente de esta contradieción o confusión dialéctica combinada, circunstancia que en cierta manera le ha permitido ver el fondo de una realidad que sufre de tantos matices culturales (...) Sin embargo, ésta es la linea abierta, universalizante, que ha logrado romper la linea estética y academizante a que estaba sometida la poesia por causa del intransigente conservadurismo de tipo hispánicon.

Uriel Giraldo Alvarez, llegó en olorpúblico de poesia en 1987. con un poemario declarado finalista por la Universidad de Antioquia, «Al borde de la vian, un titulo con resonancias de poesia "Beab, mas emparentado con la experiencia ur- barta, con el caracter itinerante y móvil evocado por la poesia moderna. En esa época, doce años atras, Unel nos advertia que uAfuera pasan cosas carros gentesw (4). Esa advertencia alcanzaba a toda una generacion de muy jóvenes poetas que buscaron en las hermosas y frias noches del barrio Chipre en Manizales un tono distinto, más ligero, menos ampuloso: en fin, esas aspiraciones que una poética temprana alberiga desde el corazon de la provincia, cuando reconoce que su mundo, no es aquel de tos viejos poetas caldenses, epigonos de la catolicidad hispanica de la pnmera mitad de siglo, sino aquel poeta que nos despierta bruscamente, *...con el ruido puntual/de una moto que se enrumba / hacia una fábrican. (5)

De ese primer poemario hasta llegar a la Insistencia en la tierra, nos encontramos con una serie de titulos "Visionesw, Calle 13 carrera $13 "$, "Aquel amor ya nostaigian, donde el poeta ensaya continuidad y búsqueda en las alternativas que ofrece su propia provincia, su ciudad, los particulares rasgos que la palabra traza, en los

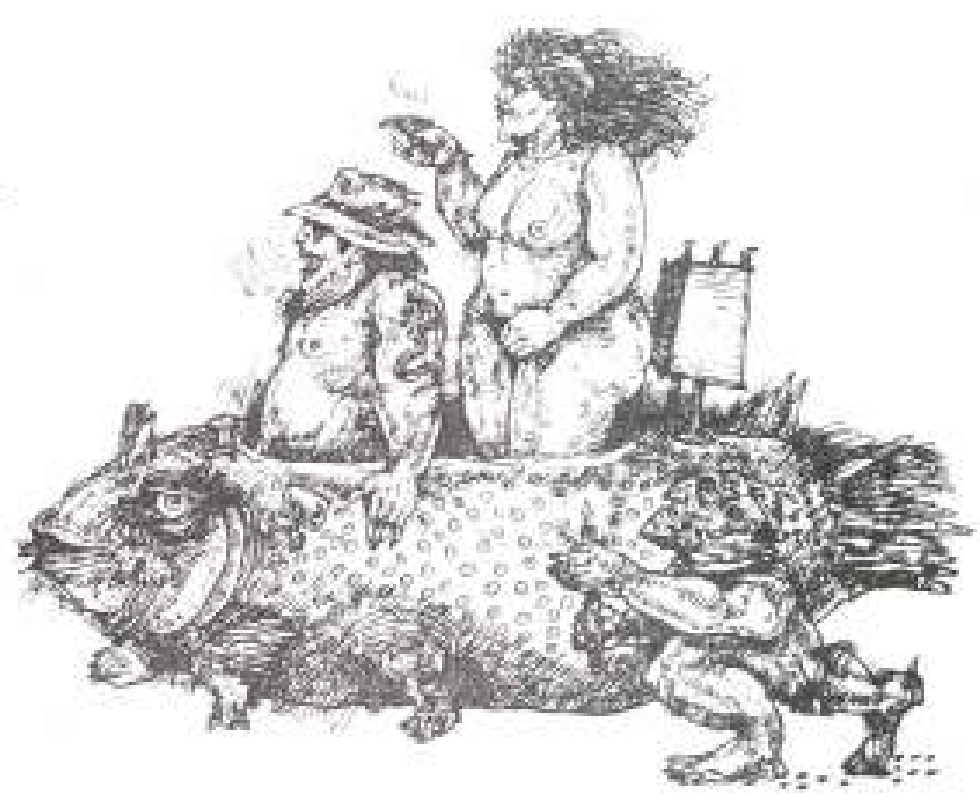




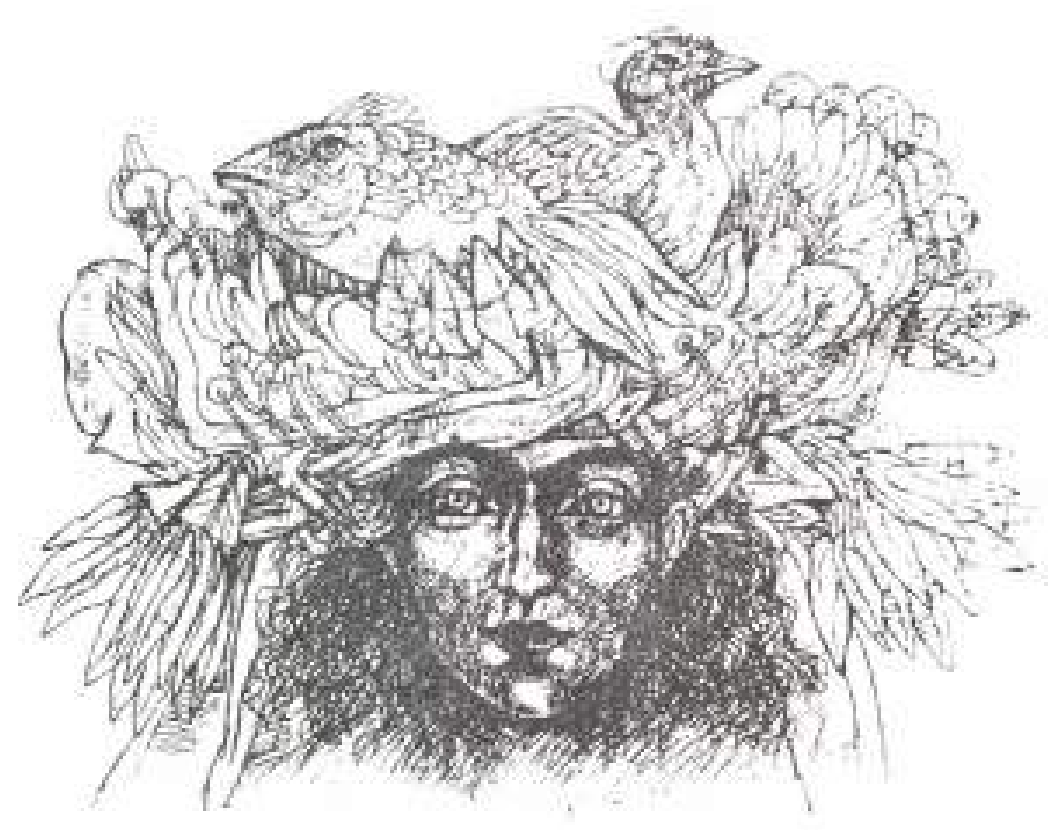

cuales comprendemos el modo que el desgarramiento moderno aumenta de volumen en la poesia, y la manera en que esta ruta se articula en el acto de nombrar calles, intuiciones elementales convergidas en la palabra como zona elemental y franca del poema. Como bien lo escribió Jorge Hurtado, otro prosista caldense de mediados de siglo: wLa provincia fue por mucho tiempo un recodo del humanismo. Existian el ensayista, el pedagogo, el filósofo y el poeta. Las ciencias arduas tenian entre nosotros tenaces divulgadores. Habia un respeto patriarcal a la inteligencian. (6) Esa provincia, más grande, en la que somos más solitarios, pero con igual disposición a la belleza y al lenguaje - es la que se empieza a levantar en la investagación estetica de Giraldo.

Este hace parte de una generación que llega cuando poco importan las generaciones, donde diera la impresión de que los poctas se constituyen más desde el aistamiento y la incomprensión de una sociedad presuntuosa de técnica; pero donde también los poetas asumen su recodo del camino, su pequeña provincia dado para nombrar y legitimar. De allí que la «Insistencia en la tierraw nos remita a mencionar dos posibles lecturas del como el espacio que les fue acto poético: la ciudad y la provincia. En ambases la idea del espacio la que se ensancha, la que crece y sobrepasa a la del tiempo, tan cara a los presupuestos racionalistas y eficientistas. Es tambien la idea del espacio la que se convierte en un topos, análogo al del bamo, el parque, el transporte público. Reclamar para ta poesia aquel espacio, tiene que ver con la legitimacion de una tierra y unas ciudades que merecen nombrarse. desde las cuales, a través de la ventana del autobús, es posible volver a sentirlas en el reclamo esencial de lo que es el paisaje primero del hombre.

recubierto con las imágenes y el agregado que las lecturas sucesivas de los poetas depositan en nosotros. En palabras de Vinicius de Moraes (7): $*$ Es prectso, es absolutamente preciso que todo sea bello e inesperados.

La poesia de Uriel Giraldo ha recordado a los escasos lectores de poesia en Manizales que el idilico paisaje de su ciudad ha sido poblado por mendigos que se masturban sin prisa junto a las vallas publicitarias, sobre los lotes de engorde que son preparados para ta especulación financiera. También ha recordado a muchos, la dura experiencia de perder el pueblo 


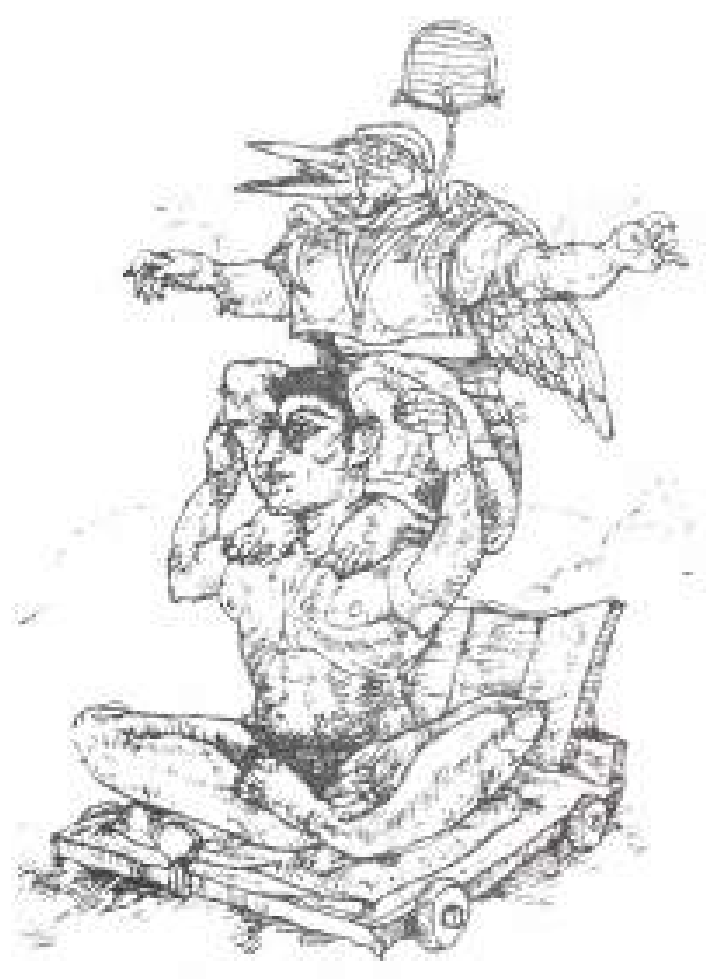

anclado en las montafias -Salamina, en el caso de Uriel-para marchar a la Manizales de lègendarios políticos y retóricos. Esa pérdida, amarga para una Colombia campesina que se urbanizo a estallidos de violencia, e insinuaciones de consumo desde algún radio o una pantalla empotrados en lo alto de un cafetin de aldea, la evoca Uriel \&...cuando llego a casa/... / y recuerdo que en tardes calurosas / como las de estos dias / al regreso de la escuela veredal / soliamos estirarnos en un prado / con divisa a lodas partes/s (8).

Fue Charles Baudelaire, uno de los tempranos poetas en evocar la experiencia de la vida urbana. Como bien lo escribe José Angel Ciruello «Quien dice París, evidentemente dice la ciudad, pues conforme, todas las pequeñas ciudades del XIX han ido alcanzando atributos parisinos (las multitudes, el dinamismo anónimo, los bajos fondos...) (9) De alli que para cada poeta, los mayores y los menores, aquellos de las grandes ciudades y los de provincia, con su propia ciudad a cuestas, resulten propensos a que en sus versos y ritmos emerjan las palabras y evocaciones que anuncian la posibilidad no asumida del todo en Uriel Giraldo, de una poética de la ciudad.

\section{EL HUMOR}

En la estética de la poesia moderna desaparece la distincion de aquellos temas que se podian tratar de serios y de no serios, de trascendentales o intrascendentales. Este efecto paródico y humoristico en que la poesia de Uriel se muestra insistente, nos manifiesta la mofa hacia el lugar común y seco de las estrofas clásicas de la poesia colombiana. Veamos algunos de esos preciosos ejemplos. «Era papada de abadesa y ese abdomen indómito / que ya te llegó a la espalda / y sobre todo / ese par de muchachiros llorando sin decoro / detrás de tu figurila deforme / y tu aire de simpleza/P_41. Nos encontramos bajos los efectos de una ironia que corrompe todo alarde de enaltecer las manidas retóricas tan caras a nuestra tradición cultural: "Ah los campesinos / ian bellas sus figuras / combadas sobre el surco / «pero ๔... no aqui a mi lado / en la buseta / con toda sufloración / de olores elementales. El humor en la poesia estí vivamente articulado a la profanación de todo elemento sagrado, a la transgresion de las reglas artificiales. El poema se elabora en serio pero se rie de si; rie del poeta, de las sensaciones y temas en que este se inspira; se burla de la aureola de trascendencia que cubriera la cabeza del poeta clásico, y que Baudelaire destrozara en el poema * La perdida de la aureola*. También, en esta Colombia de presuntos gramáticos, poetas de la talla de Luis Carios 
López. León de Greiff. y postenormente Juan Gustavo Borda han realizado una poesia que se enriquece desde el humor y que extrae de la ironia la fuerza lírica suficiente para ser poema de verdad.

Walter Benjamin afirmó que alo poético representa la unidad sintética entre el orden intelectual y el orden intuitivos (10) Lo poético moderno rompe el esquema tradicional burgués de forma y contenido. Porque a la poesia sólo se le puede nombrar desde una critica que le haga justicia al lenguaje mismo; por eso cuando Uriel escribe wemborro cuartillas y cuartillas / buscando las palabras / para que entiendas mejor /lo mucho que te necesilo /(11) no está cambiando el placer inmaterial de la palabra por el de la piel, está invitando a una continuación del texto, a una persecución de un ideal de belleza responsable de llevarnos siempre a la palabra. Se trata de una palabra que se arriesga a cruzar por este espacio donde el aura de lo clásico aparece mancillada en el suelo de los prosaismos. La palabra que se resiste a ser solo deletreada y pronunciada sino que reclama pars si el imperativo expresado por Gadamer wEjecutar permanentemente el movimiento

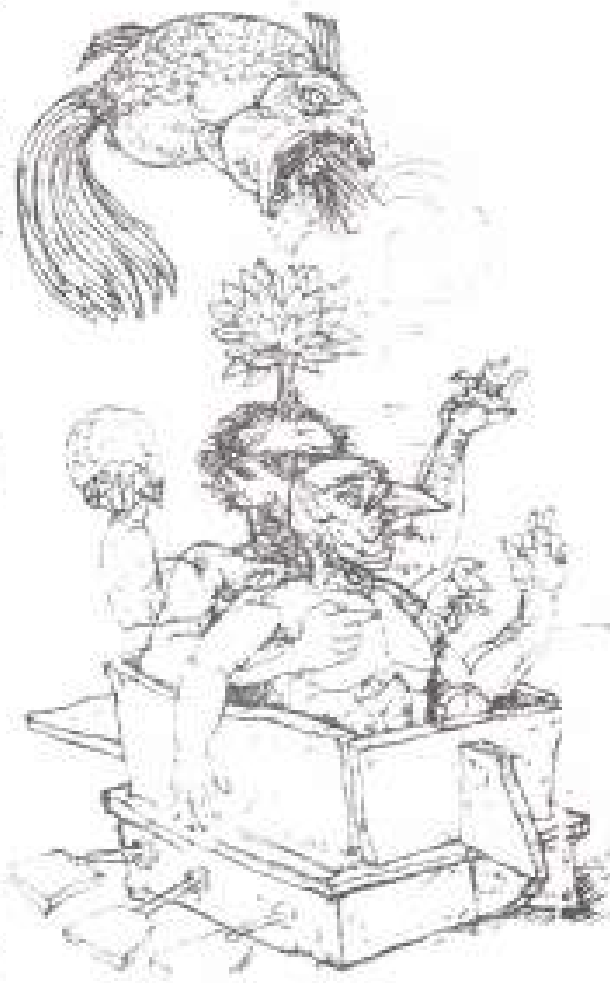

hermenéutico que gobierna la expectativa de sentido del todo y que, al final, se cumple desde el individuo eu la realización del sentido del todon.

El sentido del todo es la comunicabilidad del texto poético, la potencia de sentir la palabra no sólo como autoria del poeta sino un caudal simbólico que es herencia colectiva de lectores.

Entonces ¿qué nos dice la poesia de Uniel Giraldo? Giraldo no oculta; explora en lo prosa$c o$, remite, más allà de lo desocultado, el complejo hecho de dar significación al topos del amor en una provincia urbanizada por la sensibilidad modema.
(1) MAYA, Rafael Obra Critica. Banco de la Repüblica, p. $328, p, 17$

(2) BERMAN, Marshall Todo io sólido se desvanece en el aire. La experiencia de la modernidad. Sigio $\mathrm{XXI}$ editores, 5a edición. Santafé de Bogote. 199|

(3) ROMERO, Amando, Las palabras estan en situación. Procultara, Presidencia de la Repiblica. Nueva Biblioteca Colombiana de Cultura, 1985.

(4) GIRAL.DO, Alvarez. Uriel. Al borde de la via. Tercer Mundo. Bogota, 1988, p. 7 .

(5) Op cit, p. 9

(6) HURTADO Garcia, José. Obras Completas, Colección Alcaldfa de Manizales e Instituto Caldense de Cultura. Editorial Blanecolor. Manizales, 1997

(7) MORAES de Vinicius. La vida vivida, 1996, El Ancora Editores, Santafé de Bogota.

(8) Op cit, p. 15.

(9) CIRUELLO, José Angel, José Maria Fonollosa poeta de la ciudad, Tomado de Revista Quimera, No. 177. Febrero de 1999, Barceiona.

(10)BENJAMIN, Walter. Metafisica de la juventud. Dos poemas de Friedrich Holderlin, p. 138, Traducción Luis Martinez de Velasco, Editorial Altaya, p. 138, Barcelona 1995.

(11) GIRALDO. Uriel. Insistencia en la tierra. p. 33. 
tengo ganas de no hacer

nada nada nada

de quedarme aqui tendido

sintiendo el olor a pasto quemado

que viene de algun lugar de la tarde

viendo la huida lenta de las nubes

ensayando formas

donde habra esta noche

un naufragio de estrellas

\section{Del libro «Insistencia en la Tierra»}

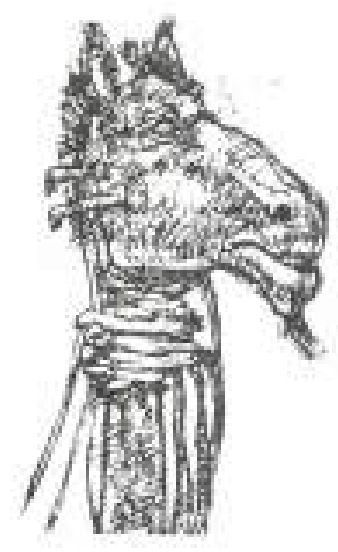

la ciudad que yo amo

es aquella sumergida en la niebla

con parejas anidandose en los parques

mientras la neblina da vuchas

por entre ios árboles

por entre los escaños

posándose en el pelo de los enamorados

en los hombros en las mejillas

en los labios

tal vez entre nosotros

estrechándonos

(a propósito

qué bien cabes

en el hueco de mi pecho)

y esel sol

apareciendo apenas al atardecer

rojo furioso

luchando entre nubes

para iniciamos

en largas noches

de caricias 


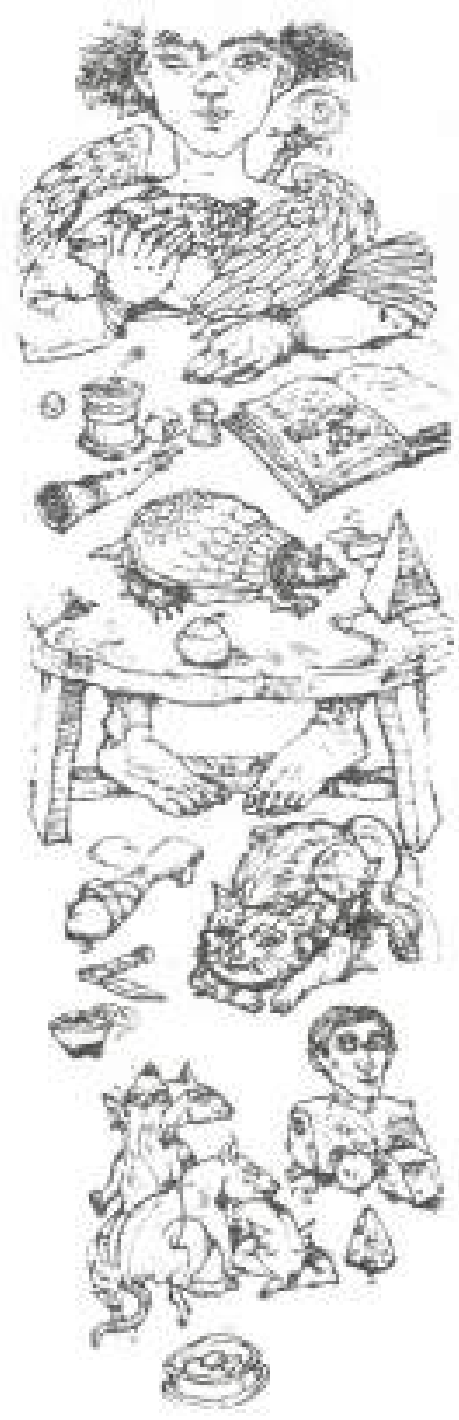

Alguien fue muerto hoy

Alguien que no estaba de acuerdo con este estado de cosas

Los noticieros registraron el hecho con profusión de imàgenes

Los politicos en campaña lo deploraron

y dijeron a una

que las cosas tienen que cambiar

Lapolicia inició

una exhaustiva investigación

y sus copartidarios pidieron

que el crimen no quede impune

Alguien fue muerto boy

y sin embargo

pasaron puntuales

la seriora de las tortas de choclo

el carrito de la mazamorra desafiando la lluvia

y las busetas cada tres minutos

Pero ios muchachos

de este barrio de pobres

hory sin estudios por temor a disturbios

juegan en un barranco

cual si fuera domingo

con una pelota

que a cada goipe

hay que salir tras ella falda abajo

$y$ uno insiste

en elevaren abril

una cometa

y me hace pensar

enalguien

otro

que fue muerto hoy 